\title{
Thymoma with Hypogammaglobulinaemia in an Identical Twin
}

\author{
SIMON GODFREY,* M.B.
}

Brit. med. F., 1964, 1, 1159-1160

The relation of the thymus to immunological processes has recently been reviewed by Miller et al. (1962) and by Miller (1963). Good (1954) first reported the association of a thymoma with agammaglobulinaemia resulting in the antibody-deficiency syndrome. This paper describes the first known occurrence of the association in an identical twin, the other twin being normal, thus showing the defects to have been truly acquired.

\section{Case Report}

The patient was a 63-year-old married woman. There was no family history of protein disorders, thymic tumours, or any of the known associated conditions. She has an identical twin. Apart from peritonitis following appendicectomy at the age of 54, she was well until December 1962, when she developed a productive cough following the smog.

In February 1963 she was admitted to Hammersmith Hospital with an acute chest infection (Fig. 1). Her sputum was purulent and Haemophilus influenzae was cultured. She made a slow recovery over the next month, but her productive cough continued and $x$-ray changes suggestive of bronchiectasis were noted.

In April she was readmitted as a surgical emergency with an obstructed abdominal hernia through a laparotomy scar. This rapidly settled on conservative treatment. Serial chest $x$-ray films showed a mass in the anterior mediastinum (Fig. 2), which was rapidly neutralization was 1/16 normal. Sternal marrow puncture showed normal haemopoiesis but absence of plasma cells and slightly

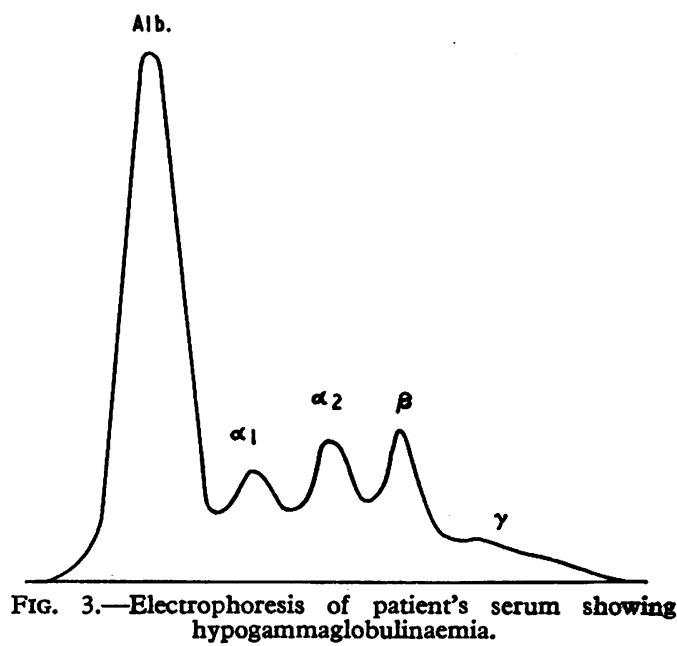

increased iron stores. Blood group was A rhesus positive with absent anti-B isoagglutinin; thymol turbidity nil ; zinc sulphate turbidity nil. Other investigations were essentially normal.

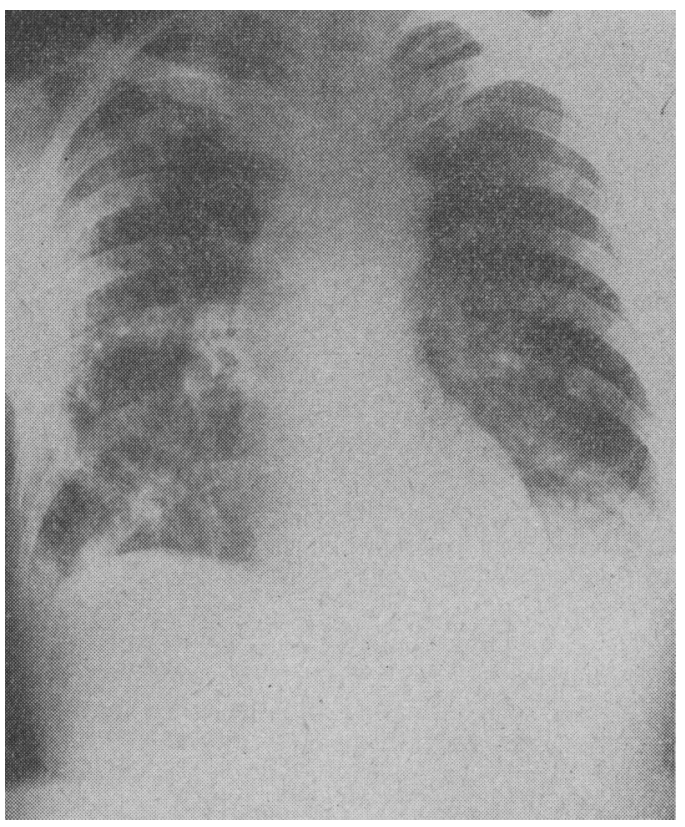

Fig. 1

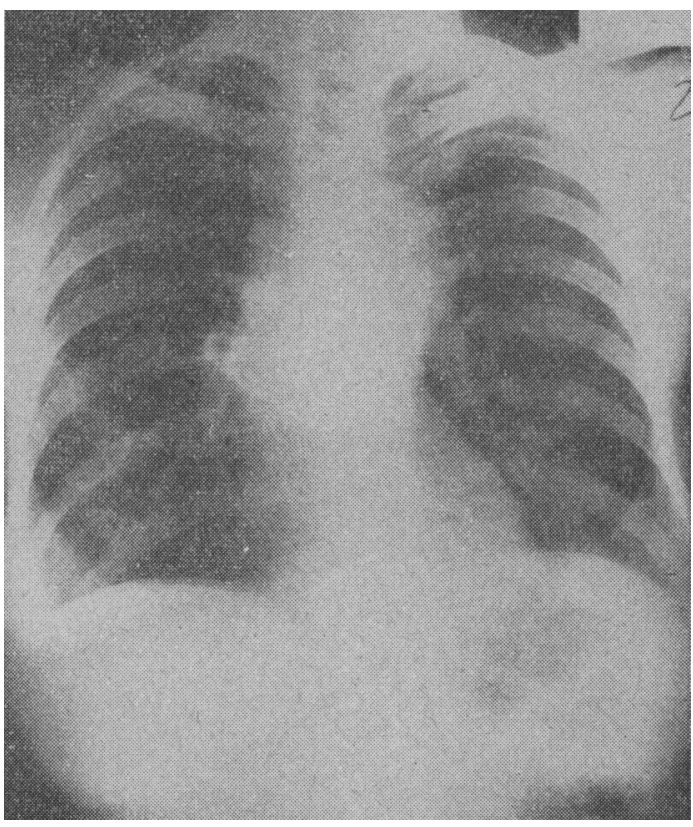

FIG. 2

Fig. 1.-Chest $x$-ray film showing diffuse inflammatory changes. Fig. 2.-Chest $x$-ray film showing development of mediastinal shadow and clearing of inflammatory changes.

enlarging. Further investigations showed: haemoglobin $11.8 \mathrm{~g} . / 100$ ml. ; W.B.C. $6,000 /$ c.mm., with normal differential count ; serum albumin/globulin (A/G) ratio 3.7/2.1. Serum electrophoresis (Fig. 3) revealed marked hypogammaglobulinaemia. Antigammaglobulin

* From the Department of Medicine, Hammersmith Hospital and Postgraduate Medical School, London. At present House-physician, Medical Unit, Brompton Hospital, London.
On 13 June thoracotomy was performed by Mr. M. Omeri and a lobulated mass was removed from the anterior mediastinum. There was no evidence of invasion of the surrounding tissues. The tumour, which weighed 220 g., was reported upon by Dr. T. Westgarth as follows: "A lobulated thymoma of characteristic structure with an intimate mixture of epithelial cells and lymphocytes in about equal proportions. Conclusion-benign thymoma." 
Post-operatively the patient received a short course of deep $x$-ray therapy to the mediastinum. For the next two months she ran a persistent pyrexia, and coughed up as much as $100 \mathrm{ml}$. of foul sputum daily. $H$. influenzae was frequently cultured from the sputum in spite of theoretically adequate antibiotic therapy.

Examination at that time revealed clubbing of the nails, with coarse crepitations over both lower lobes. She was treated by postural drainage and antibiotics (chloramphenicol total $12 \mathrm{~g}$., ampicillin, and tetracycline). Her pyrexia subsided and her sputum decreased in amount. It was concluded that she had bronchiectasis secondary to hypogammaglobulinaemia. Further investigation showed: Hb 11.6 g./100 ml. ; M.C.H.C. $31 \%$; R.B.C. $3,500,000 /$ c.mm. ; reticulocytes $0.4 \%$; W.B.C. $4,000 /$ c.mm. (neutrophils $59 \%$, lymphocytes $31 \%$, monocytes $9 \%$, eosinophils $1 \%$ ); platelets $233,000 /$ c.mm. A/G ratio was 3.0/2.3. Electrophoresis showed persistent hypogammaglobulinaemia.

A second sternal-marrow puncture again showed absence of plasma cells.

A sample of blood was sent to Dr. J. F. Soothill at the Department of Experimental Pathology, University of Birmingham. $\mathrm{He}$ found a very low serum $\gamma$-globulin $(200 \mathrm{mg} . / 100 \mathrm{ml}$.) and little or no normal $\gamma_{1 \mathrm{~A}}$ - or $\gamma$-macroglobulin, but apparently abnormal proteins related to these two immunoglobulins were present. Her urine contained no protein.

\section{Observations on Identical Twin}

At this stage her identical twin was seen and she agreed to undergo some investigations. She was a married woman with one healthy child and no symptoms or signs of pulmonary or systemic disease.

Uniovular origin of the twins was established by blood-group phenotyping and by cross-over skin-grafting which was performed

Observations on Identical Twin Compared with Patient

\begin{tabular}{|c|c|c|}
\hline Observation & Patient & Twin Sister \\
\hline 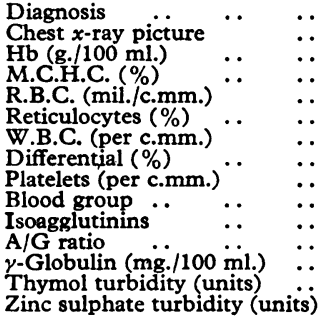 & $\begin{array}{l}\text { Bronchiectasis } \\
\text { Basal bronchiectasis } \\
11 \cdot 6 \\
31 \\
3 \cdot 5 \\
0 \cdot 4 \\
4,000 \\
\text { P.59, L. 31, M. 9, E. } 1 \\
233,000 \\
\text { A positive } \\
\text { Absent } \\
3 \cdot 0 / 2 \cdot 3 \\
200 \\
0 \\
0\end{array}$ & $\begin{array}{l}\text { Normal } \\
12 \cdot 0 \\
30 \\
4 \cdot 6 \\
0 \cdot 4 \\
5,000 \\
\text { P.61, L. 28, M. 11, E. } 0 \\
235,000 \\
\text { A positive } \\
\text { Present } \\
3 \cdot 9 / 3 \cdot 4 \\
1,920 \\
3 \\
5\end{array}$ \\
\hline
\end{tabular}

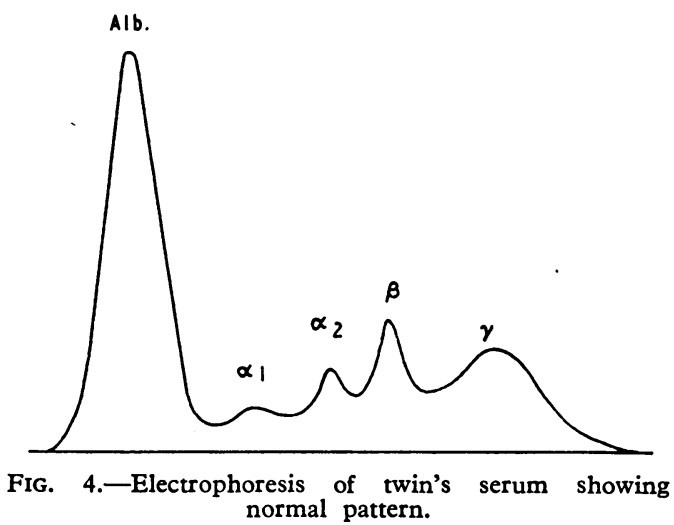

by Mr. J. S. Calnan. It was noted that the normal twin accepted skin from her sister but rejected that from a stranger after 12 days, while the patient accepted skin from both her sister and the common unrelated donor until her death four weeks later.

In the Table the observations on the healthy twin are compared with those of the patient. Her electrophoretic strip is shown in Fig. 4. Dr. Soothill estimated her immunoglobulins and found them to be normal.

\section{Terminal Illness}

At the end of October the patient became increasingly drowsy and inaccessible. She passed into a somnolent state and became incontinent, but there were no localizing neurological signs. Lumbar puncture showed protein $140 \mathrm{mg} . / 100 \mathrm{ml}$. and 10 cells per c.mm. A carotid angiogram was suggestive of hydrocephalus, and so she was transferred to the Maida Vale Hospital for Nervous Diseases under the care of $\mathrm{Mr}$. Valentine Logue. A ventriculogram revealed a communicating hydrocephalus but no localized lesion, and she died on 21 November. Permission for necropsy was refused.

\section{Discussion}

The association of acquired hypogammaglobulinaemia with the reticuloses is well known (Page et al., 1963), and it is becoming evident that it also occurs with about $6 \%$ of thymomas (Gafni et al., 1960). The tumour is usually a benign lymphoepithelioma or spindle-cell thymoma, but the condition has also been described with follicular hyperplasia (Miller et al., 1962) and metastasizing spindle-cell carcinoma (Gafni et al., 1960). In many cases an erythroblastic hypoplasia has been found (Ramos, 1956 ; Lambie et al., 1957), but there was no evidence of this in the present case.

The identical twin of the patient described above has normal plasma proteins. This fact, together with the onset of symptoms late in life, suggests that the patient lost the ability to form immunoglobulins at the onset of her illness. This was associated with the rapid appearance of a neoplasm of the thymus, an organ known to be intimately concerned with immunological processes. The detection of circulating abnormal proteins suggested the possibility of myeloma, but her E.S.R. was never above $30 \mathrm{~mm}$./hour and her urine was free from protein. $X$-ray films of her bones were normal, and the sternal marrow contained no abnormal cells. However, it is possible that such cells were present elsewhere.

The cause of death of the patient was unfortunately not established, but the most likely possibility was a cerebral abscess. We had hoped to perform a transfer of marrow from the normal twin in an attempt to establish new clones of immunologically competent cells. This would have been preferable to treatment with exogenous globulin, but neither method could reverse the damage already done to the lungs.

\section{Summary}

A case is described of acquired hypogammaglobulinaemia in an adult associated with a benign thymoma. The identical twin of the patient was normal. Removal of the tumour failed to affect the gamma-globulin level. The prospect of transferring immunologically competent cells from the normal twin to the patient was considered, but she died of hydrocephalus of uncertain origin before this could be performed.

I wish to thank the many members of the staff of the Hammersmith Hospital who have helped with the investigation of this case, Dr. E. J. M. Campbell and the other consultants concerned have kindly given me permission to publish this report, and Professor I. D. P. Wootton, Dr. J. F. Soothill, Dr. R. G. White, and Dr. C. M. Fletcher gave much help and encouragement in its preparation.

\section{REFERENCES}

Gafni, J., Michaeli, D., and Heller, H. (1960). New Engl. 7. Med., 263,

Good, R. A. (1954). Bull. Univ. Minn. Hosp., 26, 1.

Lambie, A. T., Burrows, B. A., and Sommers, S. C. (1957). Amer. 3. clin. Path., 27, 444.

Miller, J. F. A. P. (1963). Brit. med. F., $2,459$.

Marshall, A. H. E., and White, R. G. (1962). Advanc. Immunol.,

Page, A. R., Hansen, A. E., and Good, R. A. (1963). Blood, 21, 197.

Ramos, A. J. (1956). F. Amer. med. Ass., 160, 1317. 